\title{
HEALTHCARE MARKETING: AN EMPIRICAL STUDY AMONG LEBANESE HOSPITALS
}

\author{
Malak Aoun and Hassan Alaaraj \\ School of Business, Lebanese International University \\ mallakaoun@hotmail.com
}

(Received September 2017 - Accepted October 2018)

\begin{abstract}
Aoun, M. and Alaaraj, H. 2018. Healthcare Marketing: An Empirical Study among Lebanese Hospitals. Lebanese Science Journal. 19(3): 453-464.

Although most of studies have identified different dynamic factors that influence hospitals business development, there is always an increasing interest to find the best practices that ensure effective and sustainable marketing strategies in healthcare. The purpose of this study was to make an approach between patients and hospital managers to develop an effective marketing strategy for hospitals in Lebanon.
\end{abstract}

A quantitative methodology was applied to statistically test both patients and managers' attitudes through conducting two different simple surveys among patients and managers from four different hospitals in Lebanon. Self-administered questionnaires were designed in terms of marketing mix and hospitalization experience, and distributed randomly among participants to assess the implemented marketing strategies. Majority of patients were satisfied from the healthcare service provided and 93.3\% of patients showed high level of loyalty to these hospitals. In terms of experiencing the marketing mix, majority of patients were able to identify the most significant 7ps in hospitals especially in terms of price and people. Similarly, the results obtained from managers' survey showed consistency of the marketing strategies applied by these hospitals with the patients' attitudes but with some conservation regarding the pricing strategies in the Lebanese healthcare system.

The importance of healthcare marketing falls mainly in the framework of strengthening public relations with patients and maintaining a proper pricing strategy that is backed by the government and mediated by the guarantors. Future studies can be extended empirically in terms of geographical distribution of hospitals and the methodology applied.

Keywords: marketing, healthcare, patients, managers, Lebanon. 


\section{INTRODUCTION}

The quality of healthcare services in Lebanon has witnessed a paradigm shift since May 2000 from a traditional focus on physical structure and equipment to a broader multidimensional emphasis on managerial processes, performance and output indicators (Ammar et al., 2007). As this industry goes through a significant transformation, it is important for hospitals to understand what drives patients' perception of value especially that people become more habituated to develop healthy lifestyles in terms of prevention and treatment.

One of the main challenges faced by hospitals is the process of balancing its own goals and achieving an active participation in community services. It was proven that low quality hospitals are understaffed and have much lower levels of profitability than high quality hospitals (Sreenivas et al., 2013). Thus, hospitals tend to find revenue resources to finance its high quality services and enhance its competitive position as well. As discussed by Alaaraj and Aoun (2016), there is a great emphasis on developing and implementing key performance indicators (KPI) as a part of the improvement strategy to assess the hospitals' performance and monitor the quality of healthcare services in the country.

Healthcare market competition motivates hospitals to increase the quality of services provided which is a critical factor for attracting patients and gaining their satisfaction. The President of Syndicate of Private Hospitals in Lebanon, Dr. Sleiman Haroun claimed that there are two major aspects characterizing the quality of health care services in Lebanon basically; human resources and the technical supplies (Haroun, 2012). This highlights the importance of these two dynamic factors in designing a successful marketing strategy for the Lebanese hospitals. It is easier and less expensive to retain old patients than to find new ones through the marketing process (Gbadeyan, 2010).

A recent study by Aoun and Hasnan (2017) showed lack of empirical studies in the field of health care in Lebanon and the limited participation of the public health sector in these studies. However, the study highlighted the shift from implementing the hard side of total quality management that focuses on the quality control tools and statistical techniques to the soft side that is more related to the human capital and employees' involvement. Therefore, this paper highlights the marketing strategy applied by the Lebanese hospitals from two perspectives. The patients' attitudes can explain their level of satisfaction and evaluate their hospitalization experience. Also, the hospital managers can specify practically the marketing strategies applied. Thus, the objective of this study is to find an approach between patients and managers to develop an effective marketing strategy that meets the patients' expectations and benefit the hospitals in Lebanon. 


\section{LITERATURE REVIEW}

The American Marketing Association defined marketing as "an organizational function and a set of processes for creating, communicating, and delivering values to customers. It manages customer relationships in ways that benefit the organization and its stakeholders" (Gundlach, 2007). Creating the value is about developing high quality product with appropriate price. While the values of communicating and delivering are related to promotion and place respectively. These values actually represent the marketing mix- 4Ps. The term marketing mix refers to "the set of tools that the firm uses to pursue its marketing objectives in the target market" (Palmer, 2001; Kotler \& Amstrong, 2000). As for the healthcare service sector, services have different features than products because of their intangibility, heterogeneity, inseparability and perish-ability (Ahmad et al., 2013). Thus, three elements were added to the traditional model to be $7 \mathrm{p}$ 's including people, physical evidence and processes (Lovelock, 2001; Booms \& Bitner, 1981).

\section{Healthcare Marketing Mix}

In healthcare industry, product is defined in terms of providing the best means of comfort and safety, and offering the highest quality of healthcare and therapeutic services (Ferrell \& Hartline, 2005). Most products of the hospitals are services which can be classified into three categories. The line services, the supportive services offered by medical staff and lauxiliary services (Motwani \& Shrimali, 2014).

Price is used to describe the actual charge made by the hospital (Sreenivas et al., 2013). There is a direct relationship between price acceptance, satisfaction, judgments and loyalty (Consuegra et al., 2007). Also, it is suggested that hospital marketers have to adopt transparent pricing strategy which ultimately lead to higher patient satisfaction (Birchard, 2007; Griebl \& Skallca, 2007).

The third element of marketing mix is the place which refers to the contact point between health service provider and patient. For effective distribution of healthcare services, it is essential for hospitals to provide basic services at different parts of residential areas. Furthermore, hospitals' location should be easily accessed by patients especially in case of emergencies (Motwani \& Shrimali, 2014).

Promotion in marketing mix has been recently replaced by a new concept which is communications. It is related to exchange of data and information at different levels. Internal communication is among human resources inside the organization such as horizontal and topdown communication. While external communication is basically related to the interaction with customers, suppliers and surrounding market (McPhee \& Zaug, 2000).

People play key role in hospitals which include doctors, nursing staff, paramedical staff, supporting staff and front office executives. A proper 
management of human resources is critical in providing a high quality of health care services (Kabene et al., 2006). Also, doctor concern and nurse-client interaction are the most important factor affecting customer satisfaction in hospitals (Korsah, 2011; Laohasirichaikul et al., 2011).

Physical evidence is considered as an important element in the perception of service quality for patients in healthcare sector (Holder, 2008). It includes the physical and tangible commodities in terms of design, maintenance, ventilation, hygiene and all features that reflect a clean, comfort and good atmosphere for patients (Babu \& Rajalakshmi, 2009).

In hospitals, process is the operational flow of activities from the point of admission till the discharging procedures. Process may influence the initial patient decision to purchase a service and affect his satisfaction level (Collier, 1991). It has three major components; flow of activities that can be standardized or customized, number of steps (simple or complex) and customer involvement (Ahmad et al., 2013).

\section{Marketing strategy within public and private hospitals}

A general perception among patients states that private hospitals; including for profit hospitals and "not for profit" non-government providers offer better healthcare services than the public hospitals. This assumption is based on the patients' hospitalization experience in terms of comfort provided in private hospitals, the availability of high technology and the prestigious physical environment. In addition, it is well known that private hospitals can budget clever marketing and public relations campaigns (Nwazor, 2016). However, the public sector is often regarded as providing more equitable and evidence-based care. Public hospitals are generally large-sized, thus they have very low rejection rate and treat almost anyone as it is entirely run on government funding and public contributions.

Moreover, public hospitals are considered to be the better option for the lower income earners and those without medical aid. Such a debate will rage on as it is acknowledged that each system has its strengths and weaknesses, but it is confidential that both sectors are struggling financially especially in the occurrence of poor accountability and transparency in the entire health sector (Basu et al., 2012).

Recent reports of "Transparency International" regarding the Corruption Perceptions Index have ranked Lebanon 123 among 168 countries with a score of 28 /100 (Transparency International, 2015). This indicates lack of the transparency within government sector and the high level of corruption (Alaaraj \& Ibrahim, 2014). As announced by the former Minister of Public health in Lebanon, Mr. Wael Abou-Faour, this corruption have penetrated the Lebanese healthcare sector deeply and Ministry of Public Health (MOPH) is fighting corruption at different levels including food safety, medication, hospitalization, laboratories, clinics and many other departments (Abou-Faour, 2015). Therefore, this article highlights the healthcare marketing strategies among the Lebanese hospitals and narrows the points down to identify the possible opportunities and threats ahead. 


\section{METHODOLOGY}

Based on the latest 2016 Statistical Bulletin of MOPH in Lebanon, there are 147 hospitals spread throughout the country of which, 117 fall under the private sector and 30 under the public sector as shown in Figure 1 (MOPH, 2016).

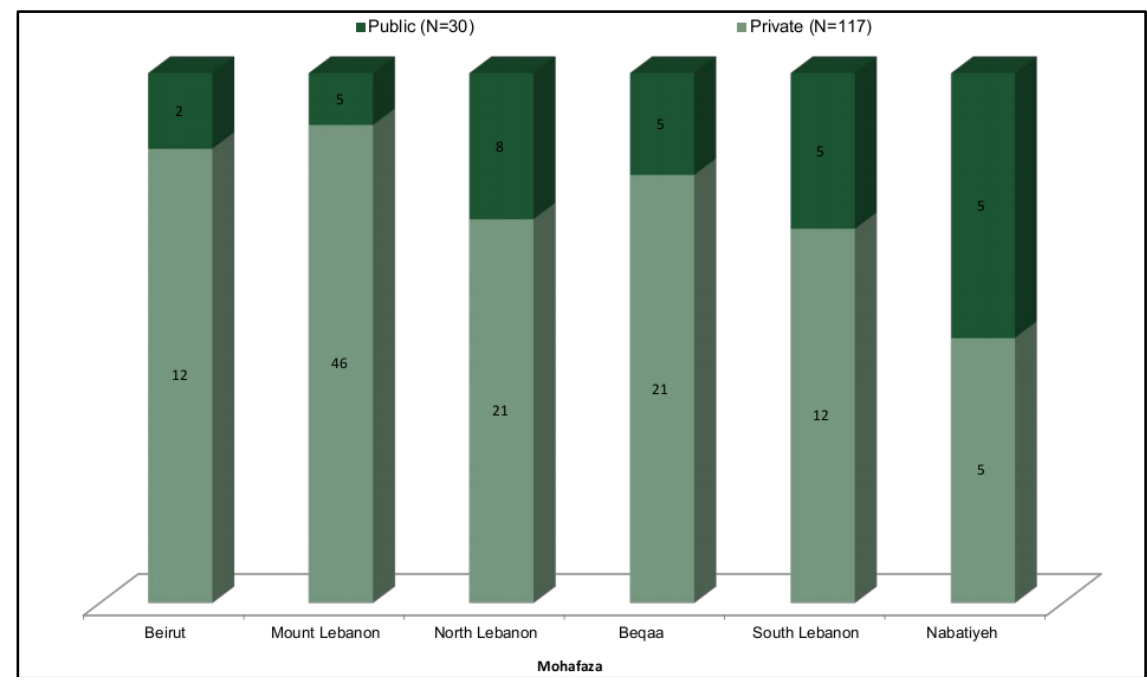

Figure 1. Hospitals contracting with MOPH by Mohafaza and type (MOPH, 2016).

The main focus of this study was on the south area of Lebanon including the two provinces; South Lebanon and Nabatiyeh. The latest list of Lebanese accredited hospitals was issued in 2014 and shows that the majority of these hospitals are accredited by MOPH as shown in Figure 2.

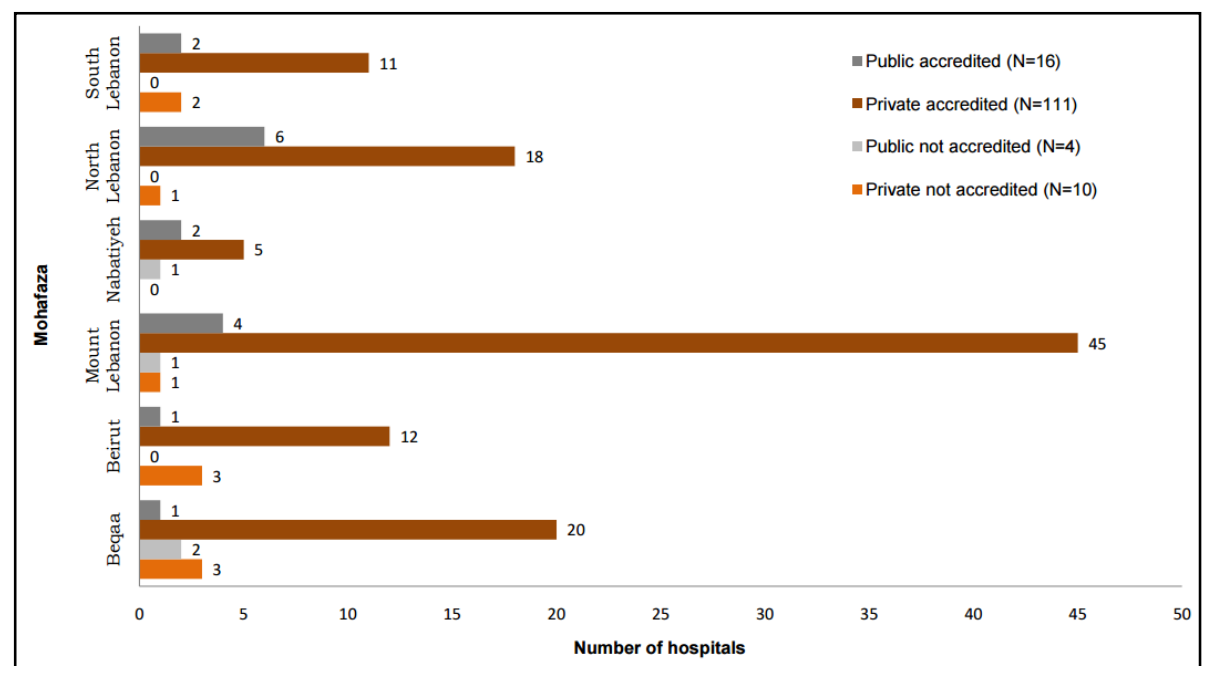

Figure 2. Number of accredited and not accredited hospitals by Mohafaza (Province) and hospital type (MOPH, 2014). 
Although there are 20 accredited hospitals from both private and public sectors in this area, only four hospitals agreed to participate in this survey: one public hospital, two private hospitals and one non-governmental organization (NGO) hospital. The hospitals' particulars are anonymous as a manner of respect for the hospitals' privacy.

Table 1 illustrates the hospitals included in the study in terms of type and size.

Table 1. Hospitals' identification in terms of type and size. Source: Upon own author elaboration.

\begin{tabular}{|c|c|c|}
\hline Hospital & Type & Minimum Number of beds \\
\hline Hospital (A) & Public & 100 \\
\hline Hospital (B) & Private & 110 \\
\hline Hospital (C) & Private & 100 \\
\hline Hospital (D) & NGO & 60 \\
\hline
\end{tabular}

A quantitative methodology was applied to statistically test the patients and managers' attitudes through conducting two different simple surveys. Self administered questionnaires were distributed randomly among patients and managers from different hospitals and results were obtained using SPSS software.

\section{Patients' Survey}

As for the survey instrument, the first part of the questionnaire specified the demographic profile of respondents in terms of gender, age, education, professional status and income. The second part included 6 direct questions to evaluate the hospitalization experience of patients in terms of marketing mix and their loyalty to the hospitals based on a 5-point Likert scale $(1=$ strongly agree to $5=$ strongly disagree (Refer to appendix 1 for complete patients' questionnaire.)).

Based on table 1, the total number of beds in these hospitals is 370 beds. Thus, it is estimated that the number of beds reflects the number of patients in these hospitals who are representing the population of this study. Based on the rule of thumb (Roscoe, 1975), a sample size larger than 30 and less than 500 is appropriate for most researches. However, a minimum sample size of 200 is required to generate valid measures (Kenny, 2015; Lei \& Wu, 2007). Hence, 200 questionnaires were distributed randomly among patients of the four hospitals and the response rate was 93.5\% where 187 usable questionnaires were returned.

\section{RESULTS}

As for the demographic profile of respondents, the majority of patients were females $(61 \%)$ and $31.4 \%$ of respondents were above 50 years old. Regarding the educational level, $38.1 \%$ of patients had less than secondary level. For the professional status, $36.2 \%$ were 
housewives; which is in line with the majority of females in the sample. Moreover, $40 \%$ of patients were average income earners; their monthly salary ranged between 700000 LP and one million LP).

Based on the patients' hospitalization experience, $65.7 \%$ of patients were not visiting the hospital for the first time and $93.3 \%$ of patients expressed their willingness to return to the same hospital when needed. Moreover, $35.2 \%$ of patients refused the idea of moving to another hospital. Therefore, majority of patients are satisfied from the services provided and they are loyal to these hospitals.

In addition, $35.2 \%$ of patients considered the medical and nursing efficiency as the main factor that drove them to the hospital and particularly the physician. Majority of patients (65.7\%) identified the hospital through their physician While $26.7 \%$ of patients had chosen the hospital because it is near their place of residence.

On other hand, $81 \%$ of patients were covered by healthcare insurance compared to $19 \%$ who paid out of their own pocket for health care expenses and 55.2\% of patients showed their satisfaction regarding the physical evidence of hospitals in terms of cleanness, safety and security.

\section{Managers' Survey}

Among the four selected hospitals, 13 managers from the top management were involved in this simple survey to understand the marketing strategies applied by these hospitals. A simple questionnaire was developed to identify the major dimensions of marketing mix based on 12 direct questions as shown in Table 2 .

Table 2. Results for hospital managers' survey. Source: Upon own author elaboration.

\begin{tabular}{|l|l|l|}
\hline \multicolumn{2}{|c|}{ Items } & Percent \% \\
\hline \multirow{2}{*}{$\begin{array}{l}\text { Best way to attract patients to your } \\
\text { hospital }\end{array}$} & Skilled medical staff & 69.2 \\
\cline { 2 - 3 } & Appropriate pricing strategy & 15.4 \\
\cline { 2 - 3 } & Technology & 15.4 \\
\hline \multirow{3}{*}{$\begin{array}{l}\text { Who is the best promoter for your } \\
\text { hospital }\end{array}$} & The doctor & 38.5 \\
\cline { 2 - 3 } & Nursing staff & - \\
\cline { 2 - 3 } & Administrative staff & - \\
\cline { 2 - 3 } & The patient & 61.5 \\
\hline Best promotion through & Media & 15.4 \\
\cline { 2 - 3 } & Public relations & 84.6 \\
\hline What are the main obstacles faced by \\
patients & Geographical access & 23.1 \\
\cline { 2 - 3 } $\begin{array}{l}\text { What factors you consider the most } \\
\text { in choosing the hospitals' location }\end{array}$ & Financial Access & 76.9 \\
\hline & Population density & 76.9 \\
\hline
\end{tabular}




\begin{tabular}{|l|l|l|}
\hline \multirow{2}{*}{ What pricing strategy do you follow? } & The competition & - \\
\cline { 2 - 3 } & Accessibility & - \\
\cline { 2 - 3 } & On the basis of cost & 69.2 \\
\hline Best financial strategy & $\begin{array}{l}\text { Low prices provide profit for } \\
\text { a long time }\end{array}$ & 30.8 \\
\hline Main reason for high cost & $\begin{array}{l}\text { High operating and } \\
\text { technology costs }\end{array}$ & 64.3 \\
\hline $\begin{array}{l}\text { How to Increase the return to the } \\
\text { hospital }\end{array}$ & Quality of services & 15.4 \\
\cline { 2 - 3 } & Relation with guarantors & 84.6 \\
\hline
\end{tabular}

\section{DISCUSSION}

Based on the survey results, it is obvious that the hospitals' marketing strategy is mainly related to the public relations and particularly through the medical staff. Majority of hospital managers $(69.2 \%)$ consider that having skilled medical staff is the best way to attract patients to hospital. Furthermore, patients are also considered essential promoters for hospital service as stated by $61.5 \%$ of hospital managers. This is because patients can easily convey their hospitalization experience to the society which directly influences the intention of other patients to either choose the hospital or avoid it.

Moreover, $76.9 \%$ of hospital managers consider the financial access to healthcare services as the main obstacle faced by patients. Although $100 \%$ of managers declared that low prices provide profit for a long time, the increase in the expenses is related to the high operating and technology costs as stated by $64.3 \%$ of hospital managers. The gap in pricing strategies among hospitals is due to the lack of regulations and accountability. Majority of hospitals as indicated by $69.2 \%$ of managers apply pricing strategy based on the cost while $30.8 \%$ of managers state that hospitals are committed to prices given by the government.

The lack of commitment of hospitals to the government pricing strategies has raised many issues that are mainly affecting the patient's interest. It should be noted that based on recent statistics, $38 \%$ of the Lebanese population is covered by the government funds including the National Social Security Fund (NSSF), Civil Servants' Cooperative (CSC), military schemes mainly army, internal security forces, public security and state security, while $8 \%$ of the population is covered by private insurance companies. The remaining $54 \%$ of the population are covered by the Ministry of Public Health for healthcare services and high cost pharmaceutical (CDR, 2015).This is supported by the survey results, where $84.6 \%$ of the hospital managers emphasized the importance of strengthening the relationship with guarantors to increase the hospital's benefits as they represent a major source of healthcare financing. Thus, hospitals along with government have to set up pricing strategies that best benefit the patients and the hospitals as well. 


\section{CONCLUSION}

The empirical findings shows that the importance of healthcare marketing falls mainly in the framework of strengthening public relations with patients and maintaining a proper pricing strategy that is backed by the government and mediated by the guarantors. Government attentions are required to improve the existing healthcare marketing strategies among both, public and private sectors. Financial support, transparency and accountability are essential aspects to fight corruption and strengthen the hospitals' potential in providing the basic healthcare needs of the people. With the limitation of this study, more comprehensive studies may be conducted by focusing on different marketing dimensions. Also, this study was limited to one area in Lebanon. Therefore, it is needed to extend this survey in terms of sample size, geographical distribution of hospitals and the methodology applied. Future studies can provide more understanding about the healthcare marketing among public and private hospitals with a more comparative manner and offer more analyses on the best practices to inspire health professionals and policy makers in Lebanon and nearby countries to strengthen health systems and increase access to quality essential services.

\section{REFERENCES}

Abou-Faour, W. 2015. Reform and the fight against corruption in the health sector is a great task. Lebanon 24.

Ahmad, A., et al. 2013. The impact of marketing mix strategy on hospitals performance measured by patient satisfaction: an empirical investigation on Jeddah private sector hospital senior managers' perspective. International Journal of Marketing Studies; 5(6): 210-227.

Alaaraj, H., and Aoun, M. (2016). Financial performance indicators in Lebanese hospitals: A sustainable improvement strategy. Journal of Accounting and Finance in Emerging Economies, 2(2): 69-75.

Alaaraj, H., and Ibrahim, F. 2014. Does practicing good governance enhance the public trust towards the Lebanese government? International Journal of Scientific and Research Publications, 4(10): 402.

Ammar, W., et al. 2007. Accreditation of hospitals in Lebanon: A challenging experience. Eastern Mediterranean Health Journal, 13(1):138-49.

Aoun, M. and Hasnan, N. 2017. Health-care technology management: developing the innovation skills through implementing soft TQM among Lebanese hospitals. Total Quality Management \& Business Excellence, 28(1-2): 1-11.

Babu, S., and Rajalakshmi, K. 2009. Marketing mix for hospital services in the globalized era. Basu, S., Andrews, J., Kishore, S., Panjabi, R., and Stuckler, D. 2012. Comparative performance of private and public healthcare systems in low- and middle-income countries: A systematic review. PLoS Medicine, 9(6): 100-124.

Birchard, S., et.al. 2007. Health Care Price Transparency: A strategic perspective for state government leaders. Deloitte Center for Health Solutions, 1-24.

Booms, B., and Bitner, M. 1981. Marketing strategies and organization structures for services firms. In James Donnelly \& William George (Eds.), Marketing of services: 1981 special educators' Conference Proceeding (pp. 46-51). Chicago: American Marketing Association. 
CDR. 2015. Public Health: Social and Economic Sectors. Report published by the Council for Development and Reconstruction. pp. 58-66.

Collier, D. 1991. New marketing mix stresses service. The Journal of Business Strategy, 12(2):42-45.

Consuegra, D.M., Molina, A., and Esteban, A. 2007. An integrated model of price, satisfaction and loyalty: an empirical analysis in the service sector. Journal of Product \& Brand Management, 16(7): 459-468.

Ferrell, O.C., and Hartline, M.D. 2005. Marketing Strategy. 3rd ed. USA: Thomson SouthWestern.

Gbadeyan, R A. 2010. Health care marketing and public relations in not for profit hospitals in Nigeria. International Journal of Business and Management; 5(7): 117-125.

Griebl, O., and Skallca, C. 2007. The growing imperative of effective pricing strategies and tools for not-for-profit hospitals. Healthcare Financial Management. October: 76-80.

Gundlach, G. 2007. The American Marketing Association's 2004 definition of marketing: perspectives on its implications for scholarship and the role and responsibility of marketing in society. Journal of Public Policy \& Marketing, 26(2): 243-250.

Haroun, S. 2012. An interview with Dr. Sleiman Haroun, Health Care Sector in Lebanon: Syndicate of Private Hospitals.

Holder, S.M. 2008. Changes in physical evidence and the perception of service quality of patients in a hospital facility. Masters dissertation: The University of Johannesburg.

Kabene, SM., Orchard, C., Howard, JM., Soriano, MA., and Leduc, R. 2006. The importance of human resources management in health care: A global context. Journal of Human Resource for Health, 4(20): 1-17.

Kenny, D. 2015. Measuring model fit.

Korsah, A. K. 2011. Nurses' stories about their interactions with patients at the Holy Family Hospital Techiman; Ghana. Open Journal of Nursing, 1: 1-9.

Kotler, P., and Amstrong, G. 2008. Principles of Marketing. $\left(12^{\text {th }}\right.$ ed $)$. New Jersey: Pearson Prentice Hall.

Laohasirichaikul, B., Chaipoopirutana, S., and Combs, H. 2011. Effective customer relationship management of health care: a study of hospitals in Thailand. Journal of Management and Marketing Research, 6(1).

Lei, P., and $\mathrm{Wu}, \mathrm{Q}$. 2007. Introduction to structural equation modelling: issues and practical considerations. Educational Measurement: Issues and Practice, 26: 33-43.

Lovelock, C. 2001. Services Marketing People, Technology, Strategy (4 ${ }^{\text {th }}$ Ed.) New Jersey: Prentice Hall.

McPhee, R., and Zaug, P. 2000. The communicative constitution of organizations: A framework for explanation". Electronic Journal of Communication/La Revue Electronique de Communication ,10(1-2): 1-16.

MOPH. 2016. Statistical Bulletin 2016. Beirut: Ministry of Public Health. MOPH. 2014. Statistical Bulletin 2014. Beirut: Ministry of Public Health.

Motwani, D., and Shrimali, V. (2014). Service marketing mix of Indian hospitals: a critical review Czech Journal of Social Sciences, Business and Economics; 3(2): 65-72

Nwazor, T. (2016). Private or public hospitals? 5 things to consider before making your health care choice. 
Palmer, A. (2001). Principles of Services Marketing (3rd ed.). UK: McGraw-Hill Publishing Company.

Roscoe, J. (1975). Fundamental research statistics for the behavioral science. US: Holt, Rinehart \& Winston, Inc.

Sreenivas T., Srinivasarao B. and Srinivasa Rao U (2013). An Analysis on Marketing Mix in Hospitals. Advances in Management, 6(2): 46-55.

Transparency International. (2015). Corruption Perceptions Index 2015. 


\section{ANNEXE}

\section{Appendix 1: Patients' Questionnaire}

\begin{tabular}{|l|ll|}
\hline \multicolumn{3}{|c|}{ Part 1: Demographic profile } \\
\hline Gender & 1. & Male \\
& 2. & female \\
\hline Age & 1. & $10-20$ \\
& 2. & $21-30$ \\
& 3. & $31-40$ \\
& 4. & $41-50$ \\
& 5. & $50+$ \\
\hline Educati & 1. & less \\
on & 2. & High school \\
& 3. & Degree \\
& 4. & Master \\
& 5. & PhD \\
\hline Profess & 1. & unemployed \\
ional & 2. & House wife \\
status & 3. & Student \\
& 4. & Employee \\
& 5. & free business \\
& 6. & Retired \\
\hline Income & 1. & Less \\
& minimum than \\
& 2. & 700 million LP. \\
& 3. & 1 \\
& million LP Million-2 \\
& 4. & More than 2 \\
& million LP \\
\hline
\end{tabular}

\section{Part 2: Hospitalization Experience}

Is this your first visit to the hospital?

1. Yes

2. No

Are you ready to return to the hospital when needed?

1. Yes

2. No

When do you think about moving to another hospital?

1. Never

2. Less costs

3. Better quality of health services

4. New and diverse services

How did you identify this hospital?

the family

1. friends

2. Advertising

3. Internet

4. Physician

What is the factor that most drove you to this hospital?

1. medical and nursing staff efficiency

2. the development of medical equipment and devices

3. hospital location

4. Hospitality Services

5. responsiveness and quality of health services speed

6. the appropriate price

How do you participate in paying the costs?

1. Cash

2. insurance

Are you generally satisfied regarding the physical environment of the hospital (in terms of cleanness, safety and security)?

1. Yes

2. No 